\title{
Assessment of Prevalence of Iron Deficiency Anemia among Known Population
}

\author{
Gautam Gupta', Mangat Ram Passi ${ }^{2}$ \\ ${ }^{1}$ Assistant Professor, Department of Medicine, Muzaffarnagar Medical College, Muzaffarnagar, UP, India, ${ }^{2}$ Assistant Professor, Department of Medicine, \\ Shridev Suman Subharti Medical College, Dehradun, Uttarakhand, India.
}

\section{Abstract}

Background: The most significant and common cause of anemia is iron deficiency. Hence, we planned the present study to assess the prevalence of iron deficiency anemia among known population. Subjects and Methods: A total of 350 subjects who reported to the department of internal medicine for routine checkup were included in the present study.Blood samples were obtained from all the subjects and were sent to central laboratory for the assessment of blood hemoglobin levels. Criteria described in the past literature were used for categorizing patients with iron deficiency anemia. Females with mean hemoglobin concentration less than $11.5 \mathrm{~g} / \mathrm{dL}$, and males with mean hemoglobin concentrations less than $14 \mathrm{~g} / \mathrm{dL}$ were categorized as anemic. 6 All the results were analyzed by SPSS software. Results: Overall prevalence of iron deficiency anemia in the present study was 15.28 percent. The overall prevalence of iron deficiency anemia was found to be higher among subjects with more than 60 years of age. Also, significantly higher prevalence of iron deficiency anemia was found among females. Conclusion: Prevalence of iron deficiency anemia was found to be higher among females and illiterates. Therefore health education programs are recommended in future for increasing the awareness of adverse events associated with iron deficiency anemia among general population.

Keywords: Iron deficiency anemia, Prevalence

Corresponding Author: Mangat Ram Passi, Assistant Professor, Department of Medicine, Shridev Suman Subharti Medical College, Dehradun, Uttarakhand, India.

Received: May 2018

Accepted: June 2018

\section{Introduction}

The most significant and common cause of anemia is iron deficiency. If iron intake is limited or inadequate due to poor dietary intake, anaemia may occur as a result. This is called iron deficiency anemia. Iron deficiency anemia can also occur when there are stomach ulcers or other sources of slow, chronic bleeding (colon cancer, uterine cancer, intestinal polyps, hemorrhoids, etc). ${ }^{[1-3]}$ Iron deficiency anaemia is prevalent worldwide. Iron has a major role in human body. According to previous study iron is needed for various functions. Oxygen transport, DNA synthesis, and electron transport are few examples. ${ }^{[4,5]}$ Hence; under the light of above mentioned data, we planned the present study to assess the prevalence of iron deficiency anemia among known population.

\section{Subjects and Methods}

The present study was conducted in the department of general medicine of the medical institute and it included assessment of prevalence of iron deficiency anemia. Ethical approval was obtained from institutional ethical committee and written consent was obtained after explaining in detail the entire research protocol. A total of 350 subjects who reported to the department of internal medicine for routine checkup were included in the present study. Inclusion criteria for the present study included:

- Patients with negative history of any systemic illness,

- Patients with negative history of presence of any metabolic disorder,

- Patients with negative history of presence of any form of hematological disorder

Complete demographic and clinical details of all he patients were obtained. Blood samples were obtained from all the subjects and were sent to central laboratory for the assessment of blood hemoglobin levels. Criteria described in the past literature were used for categorizing patients with iron deficiency anemia. Females with mean hemoglobin concentration less than $11.5 \mathrm{~g} / \mathrm{dL}$, and males with mean hemoglobin concentrations less than $14 \mathrm{~g} / \mathrm{dL}$ were categorized as anemic.6 All the results were analyzed by SPSS software.

\section{Results}

In the present study, a total of 350 patients were analyzed. Mean age of the patients of the present study was 50.1 years. 
Overall prevalence of iron deficiency anemia in the present study was 15.28 percent. The overall prevalence of iron deficiency anemia was found to be higher among subjects with more than 60 years of age. Also, significantly higher prevalence of iron deficiency anemia was found among females and among illiterates.

Table 1: Overall prevalence of iron deficiency anemia

\begin{tabular}{|l|l|l|}
\hline Parameter & Number & Percentage \\
\hline Iron deficiency anemia & 50 & 15.28 \\
\hline
\end{tabular}

Table 2: Prevalence of iron deficiency anemia among subjects divided on the basis of age

\begin{tabular}{|l|l|l|}
\hline Age group (years) & Number & Percentage \\
\hline Less than 40 & 10 & 2.86 \\
\hline 40 to 60 & 15 & 4.28 \\
\hline More than 60 & 25 & 7.14 \\
\hline
\end{tabular}

Table 3: Prevalence of iron deficiency anemia among subjects divided on the basis of gender

\begin{tabular}{|l|l|l|}
\hline Gender & Number & Percentage \\
\hline Males & 20 & 5.71 \\
\hline Females & 30 & 8.57 \\
\hline
\end{tabular}

Table 4: Prevalence of iron deficiency anemia among subjects divided on the basis of literacy level

\begin{tabular}{|l|l|l|}
\hline Literacy level & Number & Percentage \\
\hline Illiterate & 22 & 6.28 \\
\hline Less than secondary & 12 & 3.42 \\
\hline Upto graduation & 10 & 2.86 \\
\hline Postgraduate & 6 & 1.71 \\
\hline
\end{tabular}

\section{Discussion}

The long phylogenetic history of the sex difference in haemoglobin levels in vertebrates indicates that males and females evolved different mean venous haemoglobin levels for different purposes, or under different selection pressures. How and why these differences are maintained, and their relevance in medical practice, have not been fully defined to date, and are the subjects of this review. Adult men and adult women have different haemoglobin levels in health. This sex difference is independent of iron status - iron replete premenopausal women have mean haemoglobin levels approximately $12 \%$ lower than age $\&$ race matched men. ${ }^{[6-9]}$ In the present study, a total of 350 patients were analyzed. Mean age of the patients of the present study was 50.1 years. Kumari $\mathrm{R}$ et al assessed the prevalence of iron deficiency and IDA in adolescent girls in a Tertiary Care Hospital. This cross-sectional study was done in the biochemistry clinical laboratory of Indira Gandhi Institute of Medical Sciences, Patna, Bihar, India for a period of six months (April 2015October 2015). Haemoglobin estimation was done by Sahli's method. Total iron and Total Iron Binding Capacity (TIBC) estimation was done by Ferrozine method on fully automated chemistry analyzer Olympus AU 400 with the reagent kit available in the market. Ferritin estimation was done by chemiluminesence immunoassay method, using Access 2 (Beckman Coulter). Out of 200 girls, 50\% adolescent girls were found to be anaemic. Of the total, $43.3 \%$ were mildly, $3.3 \%$ were moderately and $3.3 \%$ were severely affected by anaemia. As prevalence of anaemia is $50 \%$, it needs intervention for its prevention and control. ${ }^{[10]}$

In the present study, the overall prevalence of iron deficiency anemia in the present study was 15.28 percent. Ahankari AS et al investigated the prevalence and risk factors associated with IDA in rural Maharashtra, India, to address current evidence gaps. The study recruited 13- to 17-year-old adolescent girls living in 34 villages of Osmanabad district. Data were collected on individual health, dietary, sociodemographic factors, and anthropometric measurements were taken. Haemoglobin $(\mathrm{Hb})$ levels were measured using Sahli'shaemometer. Logistic and linear regressions were used to identify risk factors associated with IDA and $\mathrm{Hb}$ levels, respectively. Among 1010 adolescent girls (response rate $97.5 \%$ ), the mean $\mathrm{Hb}$ was $10.1 \mathrm{~g} / \mathrm{dl}$ (standard deviation $=$ $1.3)$, and $87 \%$ had anaemia $(\mathrm{Hb}<12 \mathrm{~g} / \mathrm{dl})$. The prevalence of mild (11.0-11.9 g/dl), moderate (8.0-10.9 g/dl) and severe $(\mathrm{Hb} \leq 7.9 \mathrm{~g} / \mathrm{dl})$ anaemia was $17 \%, 65 \%$ and $5 \%$, respectively. Anaemia likelihood increased significantly with age (odds ratio (OR): 1.41 per year, $95 \%$ confidence interval (CI): 1.17-1.70). Factors associated with decreased anaemia risk were mid-upper arm circumference (MUAC) $\geq 22 \mathrm{~cm}$ (OR: 0.51, 95\% CI: 0.31-0.82), $\geq 3$ days/week consumption of fruit (OR: $0.35,95 \%$ CI: $0.23-0.54$ ) or rice (OR: 0.39 , 95\% CI: 0.17-0.91), and incomplete schooling (OR: 0.47, 95\% CI: 0.24-0.91). In the final model lower age, MUAC and fruit consumption were significantly associated with $\mathrm{Hb}$ level. Anaemia prevalence was extremely high among adolescent girls in rural areas of Maharashtra. ${ }^{[1]}$

In the present stud, the overall prevalence of iron deficiency anemia was found to be higher among subjects with more than 60 years of age. Also, significantly higher prevalence of iron deficiency anemia was found among females and among illiterates. Shill $\mathrm{KB}$ et al assessed the prevalence of irondeficiency anaemia among university students in Noakhali region. In the study, $55.3 \%$ students were found anaemic, of whom $36.7 \%$ were male, and $63.3 \%$ were female. Students aged 20-22 years were more anaemic (43.4\%) than other age-groups. Majority (51.3\%) of male students showed their haemoglobin level in the range of $13-15 \mathrm{~g} / \mathrm{dL}$, followed by $26.0 \%$ and $21.3 \%$ with $10-12 \mathrm{~g} / \mathrm{dL}$ and $16-18 \mathrm{~g} / \mathrm{dL}$ respectively. Although $50.5 \%$ anaemic and $51.1 \%$ nonanaemic female students showed normal BMI--lower percentage than anaemic $(60.7 \%)$ and non-anaemic $(71.9 \%)$ male students, the underweight students were found more anaemic than the overweight and obese subjects. Regular breakfast-taking habit showed significant ( $p=0.035,95 \%$ CI 0.5-1.0) influence on IDA compared to non-regular breakfast takers. Consumption of meat, fish, poultry, eggs, or peanut butter regularly; junk food; multivitamins; and iron/iron-rich food showed insignificant $(\mathrm{p}=0.097,95 \%$ CI 0.5-1.1; $\mathrm{p}=$ $0.053,95 \%$ CI $1.1-2.3 ; \mathrm{p}=0.148,95 \%$ CI $0.6-1.2$; and $\mathrm{p}=$ $0.487,95 \%$ CI $0.7-1.4$ respectively) role in provoking IDA. In the case of non-anaemic subjects, all of the above parameters were significant, except the junk food consumption $(\mathrm{p}=0.342,95 \%$ CI 0.5-1.2). Our study revealed that majority of university students, especially female, were anaemic that might be aggravated by food habit and lack of awareness. The results suggested that anaemia can be prevented by providing proper knowledge on the healthful diet, improved lifestyle, and harmful effect of 
anaemia to the students. ${ }^{[12]}$

\section{Conclusion}

Under the light of above obtained results, the authors conclude that prevalence of iron deficiency anemia was found to be higher among females and illiterates. Therefore health education programs are recommended in future for increasing the awareness of adverse events associated with iron deficiency anemia among general population.

\section{References}

1. Schmidt W, Buckhout TJ. A hitchhiker's guide to the Arabidopsis ferrome. Plant PhysiolBiochem. 2011;49:462-470.

2. Forman S, Paulley JT, Fetherston JD, Cheng YQ, Perry RD. Yersinia ironomics: Comparison of iron transporters among Yersinia pestis biotypes and its nearest neighbor, Yersinia pseudotuberculosis. Biometals. 2010;23:275-294.

3. Ganz T, Nemeth E. Hepcidin and iron homeostasis. BiochimBiophysActa. 2012;1823:1434-1443.

4. Knutson MD. Into the matrix: regulation of the iron regulatory hormone hepcidin by matriptase-2. Nutr Rev. 2009;67:284-288.

5. Weiss G. Iron metabolism in the anemia of chronic disease. BiochimBiophysActa. 2009;1790:682-693.

6. Jhurry ND, Chakrabarti M, McCormick SP, Holmes-Hampton GP, Lindahl PA. Biophysical investigation of the ironome of human jurkat cells and mitochondria. Biochemistry. 2012;51:5276-5284.

7. Lindahl PA, Holmes-Hampton GP. Biophysical probes of iron metabolism in cells and organelles. CurrOpinChem Biol. 2011;15:342-346.

8. Fuqua BK, Vulpe CD, Anderson GJ. Intestinal iron absorption. J Trace Elem Med Biol. 2012;26:115-119.

9. Pantopoulos K, Porwal SK, Tartakoff A, Devireddy L. Mechanisms of mammalian iron homeostasis. Biochemistry. 2012;51:5705-5724.

10. Kumari R, Bharti RK, Singh K, et al. Prevalence of Iron Deficiency and Iron Deficiency Anaemia in Adolescent Girls in a Tertiary Care Hospital. J ClinDiagn Res. 2017;11(8):BC04-BC06.

11. Ahankari AS1, Myles PR2, Fogarty AW2, Dixit JV3, Tata LJ2. Prevalence of iron-deficiency anaemia and risk factors in 1010 adolescent girls from rural Maharashtra, India: a cross-sectional survey. Public Health. 2017 Jan;142:159-166. doi: 10.1016/j.puhe.2016.07.010. Epub 2016 Aug 31.

12. Shill KB, Karmakar P, Kibria MG, Das A, Rahman MA, Hossain MS, Sattar MM. Prevalence of iron-deficiency anaemia among university students in Noakhali region, Bangladesh. J Health PopulNutr. 2014 Mar:32(1):103-10.

How to cite this article: Gupta G, Passi MR. Assessment of Prevalence of Iron Deficiency Anemia among Known Population. Acad. J Med. 2018;1(1):10-12.

DOI: dx.doi.org/10.21276/ajm.2018.1.1.4

Source of Support: Nil, Conflict of Interest: None declared 